\title{
By-catch Reduction in an Ocean Shrimp Trawl from a Simple Modification to the Trawl Footrope
}

\author{
Robert W. Hannah and Stephen A. Jones \\ Oregon Department of Fish and Wildlife, Marine Program \\ 2040 S. E. Marine Science Drive, Newport, Oregon 97365, USA
}

\begin{abstract}
Two footrope configurations commonly used in the ocean shrimp trawl fishery were fished side by side from a double-rigged vessel to compare catch rates of shrimp (Pandalus jordani) and by-catch. The control net footrope incorporated a traditional "tickler chain" groundline which runs below and in front of the fishing line of the trawl. The other net utilized a ladder chain groundline with a short roller section in the center, set to run under and slightly behind the fishing line. An acoustic mensuration system was used to monitor net efficiency in terms of net spread and rise. The trawl with the ladder/roller groundline caught $84 \%$ fewer slender sole (Eopsetta exilis), $49 \%$ fewer greenstriped rockfish (Sebastes elongatus) and $47 \%$ fewer juvenile rockfish (Sebastes spp.) $(<8 \mathrm{~cm}$ total length) than with the tickler chain groundline. After allowing for a wider net spread with the ladder/roller gear, catches of shrimp and other fish species were comparable for both gears. These results indicate that ocean shrimp trawls rigged with a groundline that runs behind the fishing line of the trawl fish efficiently for shrimp and marketable fish while excluding unmarketable species. The exact mechanism behind the increased by-catch escapement is unclear. We recommend underwater camera work to determine how small fish escape capture, and also testing a trawl without a groundline, using only dropper chains to maintain a constant height of the fishing line above bottom.
\end{abstract}

Key words: BRD, by-catch reduction, Pandalus jordani, shrimp, trawl

\section{Introduction}

Interest in by-catch reduction devices (BRDs) for the ocean shrimp (Pandalus jordani) trawl fishery off Oregon, Washington and California, USA, began in the 1960s with the work of High et al. (1969). As a result of this early work, trawls with equal length headropes and footropes came into use in the fishery, reducing the by-catch of smelt and herring (Pacific Fishery Management Council, 1981). The sorting trawl developed by High et al. (1969), however, did not come into common use because it was more difficult to construct and repair and caused reduced catch rates of shrimp (PFMC, 1981). Over time, fishers developed a variety of on-deck sorting devices, including sandpaper "smelt belts", to help deal with the unwanted catch of small fish, reducing their need for BRDs as a fishing tool (Jones et al., 1996).

Ocean shrimp fishers began experimenting with BRDs again in the early-1990s, in response to a large increase in the abundance of Pacific whiting (Merluccius productus) on the shrimp grounds (Hannah et al., 1996). The increased catches of Pacific whiting were so large that entire fishing grounds became unfishable without a BRD. Homemade or locally made soft-panel BRDs (Fig. 1) produced high and variable shrimp loss, along with modest exclusion efficiency, that was generally below the performance of the Nordmore grate (Hannah et al., 1996; Isaksen et al., 1992). Voluntary use of BRDs continued to grow, and $33 \%$ of active Oregon shrimp vessels were equipped with some type of BRD by 1994, although most used these devices less than $25 \%$ of the time (Jones et al., 1996). However, mandatory use of BRDs has not been implemented by any of the managing states or the Pacific Fishery Management Council and by 1998 BRD use had fallen again to virtually zero (Oregon Department of Fish and Wildlife, unpubl. data).

The reasons for the decline in use of BRDs by Oregon shrimp fishers are numerous. Resistance by fishers to the mandatory use of BRDs was based mostly on the value of the marketable by-catch, which has traditionally been retained and sold. Landing receipt data from 1987 to 1995 (see for example Lukas and Carter, 1998), show that the ex-vessel value of marketable by-catch in the Oregon ocean shrimp fishery ranged from $2 \%$ to $5.5 \%$ of the total ex-vessel 

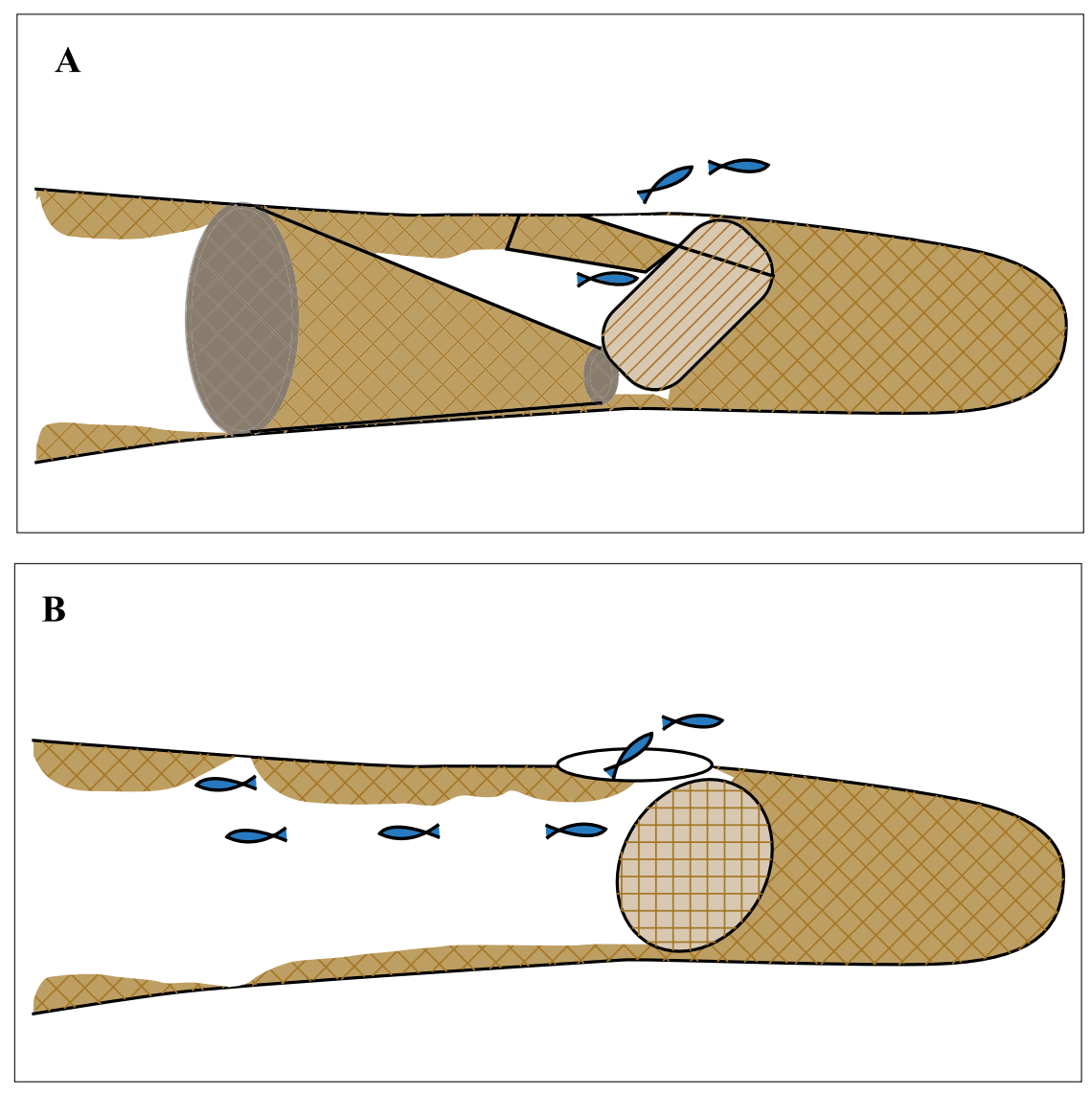

Fig. 1. Nordmore grate (A) and large mesh panel (B) by-catch reduction devices.

value from this fishery. Shrimp loss caused by the various BRDs, as well as net handling problems, contributed to the decline (Hannah et al., 1996). As in the past, fishers also developed alternative, if not ecologically friendly, ways of handling the unwanted by-catch such as "shaker grates", i.e. vibrating grates with widely spaced bars, placed between the hopper conveyor belt and the sorting belt. These devices mechanically separate larger fish from the shrimp, allowing marketable fish to be removed manually and unwanted fish to be washed overboard. Some fishers also tied weights to the codends and altered haulback procedures, allowing the net to hang vertically in the water for several minutes so that fish, primarily Pacific whiting, could escape from the mouth of the net.

A variety of factors have contributed to the reluctance by managers to make BRDs mandatory in the ocean shrimp fishery. While concerns about enforcement and tri-state coordination probably top the list, concern over the survival of excluded fish has also been raised as an issue. One alternative approach to by-catch reduction that should cause less concern about bycatch survival and be more compatible with voluntary use is the development of footrope designs that keep unwanted species from entering the trawl. The primary objective of this research was to examine differences in shrimp trawl footrope performance and their effects on ocean shrimp catch and by-catch, with the aim of identifying and developing footrope configurations that reduce by-catch.

\section{Materials and Methods}

Catches were compared between a trawl rigged with a "tickler chain" groundline (herafter called the control configuration) and a trawl with a ladder style groundline having a short-section of $6.4 \mathrm{~cm}$ disk gear in the middle (hereafter called the ladder configuration, Fig. 2). We chose these two groundline/fishing line configurations for several reasons. Most importantly they represent configurations that are in common use in the ocean shrimp fishery. The ladder 

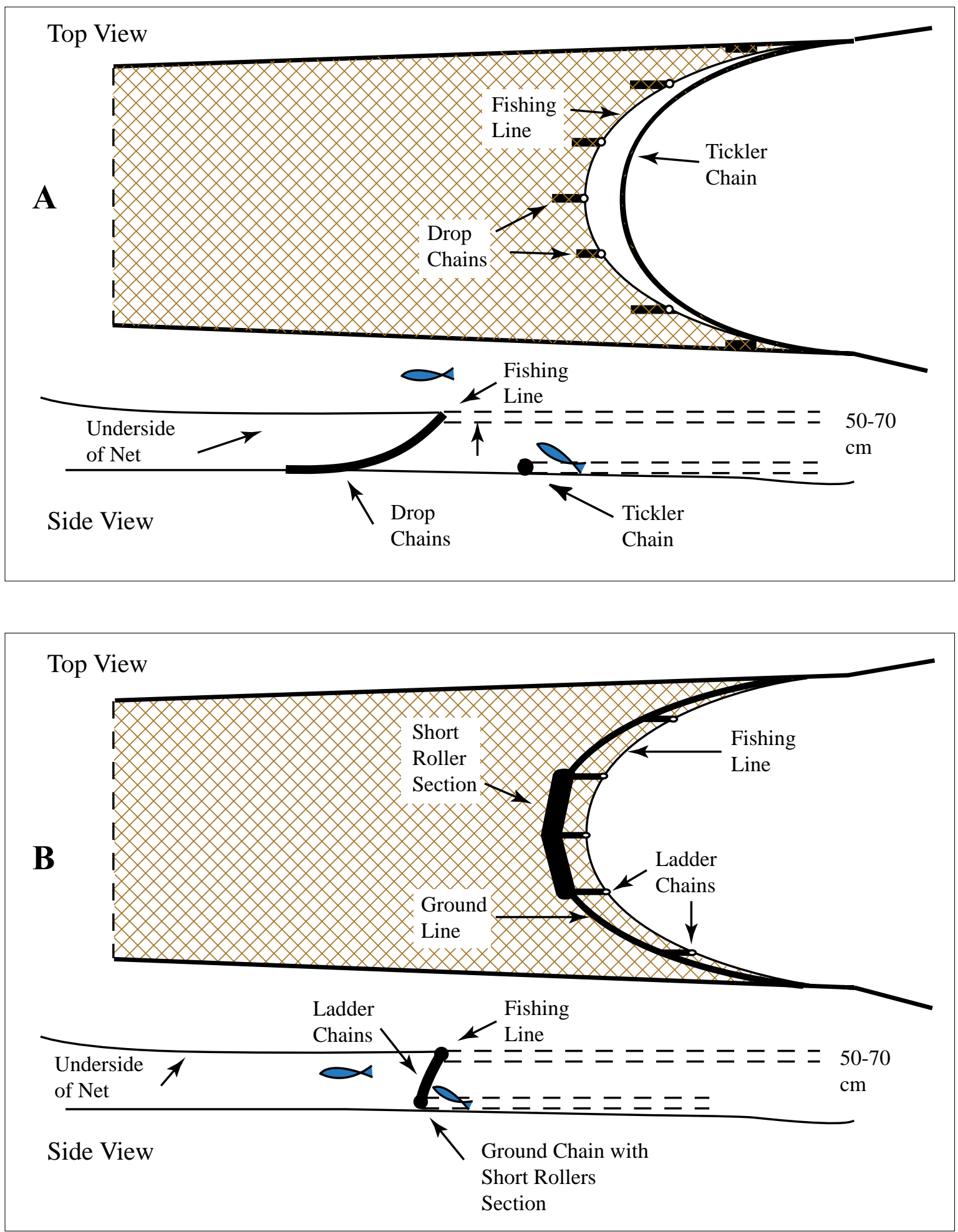

Fig. 2. Schematic of trawl footrope configurations with tickler and dropper chains (A) and with ladder/roller configuration (B). 
configuration has recently come into wide use and has been reported to fish "cleaner" by several shrimp fishers. These two configurations also incorporate an important functional difference; they have different groundline lengths, which result in differences in the relative positions of the groundlines and the fishing lines of the trawls (Fig. 2). The tickler chain is generally constructed to be shorter and run in front of and below the fishing line, causing shrimp to jump off bottom and be captured. The ladder groundline tested was slightly longer than the fishing line so that it would run directly below and slightly behind the fishing line (the setback of this line is somewhat exaggerated in Fig. 2B for clarity).

The trawl nets were of standard 4-seam design with $27.4 \mathrm{~m}$ headropes and footropes. The tickler chain itself was constructed of $25.6 \mathrm{~m}$ of $8 \mathrm{~mm}$ galvanized chain. Drop chains of various gauges were also attached at intervals along the fishing line to regulate the footrope height above bottom. These did not connect to the tickler chain, but were left to drag freely along the sea floor (Fig. 2A). In the ladder configuration, the groundline is composed of 3 sections, each about $9.2 \mathrm{~m}$ long, totaling about $27.6 \mathrm{~m}$. The two sections closest to the wings were constructed of $8 \mathrm{~mm}$ chain, while the center section was made of $6.4 \mathrm{~cm}$ rubber disks strung on a $9.2 \mathrm{~m}$ section of 13 $\mathrm{mm}$ steel cable. This groundline was attached at intervals to the fishing line, with chains that increased in length from the wings to the center of the footrope, creating the ladder configuration (Fig. 2B).

The fishing experiment was conducted on the $26 \mathrm{~m}$ double-rigged shrimper, F/V Lady Kaye, out of Newport Oregon. The control configuration was always fished on the starboard net, while the ladder configuration was fished on the port net. The use of a double-rigged vessel to compare the catch of two nets provides a powerful statistical design allowing the detection of significant differences in catch rate with far fewer tows than an alternate haul approach. However, it requires a method of controlling for differences in catch efficiency between the two nets that are not due to the effect being examined. In prior experiments this was accomplished by placing BRDs in both nets and systematically varying which BRD was active every two tows (Hannah et al., 1996). The data were then analyzed as a three factor ANOVA without interaction, using haul, side of gear and the BRD as main effects. In the present experiment it was not possible to change the footrope configuration from side to side. Accordingly, we used an acoustic trawl monitoring system to measure gear efficiency directly, i.e. the rise and spread of each net which accounted for differences in the shape of the fishing circle. The length of the unpolished part of a new section of galvanized chain attached to the fishing line of each net at the beginning of the experiment also provided an estimate of the average height of the fishing lines above bottom.

The entire catch from each tow and net was sorted and weighed separately by species or species groups (Table 1) by first emptying each codend into its respective side of a divided hopper. The catch from one side was completely sorted before sorting of the other side began. Fish and invertebrates other than shrimp were separated from the catch as it passed from the hopper over a sorting belt and placed into colour coded baskets to prevent intermixing between nets. After all shrimp processing was completed fish and invertebrates were sorted by species as required. Very small and uncommon specimens from these groups were discarded.

In order to allow meaningful comparisons for less abundant species which were present in some hauls

TABLE 1. Composition of by-catch species groups used for analysis of catch data.

\begin{tabular}{lll}
\hline \hline Species Group & Species Included & Scientific Name \\
\hline Marketable Fish & Dover sole & Microstomus pacificus \\
& Canary rockfish & Sebastes pinniger \\
& Yellowtail rockfish & Sebastes flavidus \\
& Sablefish & Anoplopoma fimbria \\
& Lingcod & Ophiodon elongatus \\
Smelt & Various & Osmeridae \\
Juvenile Rockfish & Various & Sebastes spp. \\
\hline
\end{tabular}


and not in others, and to facilitate rapid field sorting, we grouped some species together. These groups included smelt (Osmeridae), juvenile rockfish (Sebastes spp. < approx. $8 \mathrm{~cm}$ ) and larger marketable fish (Table 1). Catch data were analysed by species group as a two factor ANOVA without interaction, with haul and footrope configuration as main effects in a multiplicative model. For most species groups, the catch by weight was used as the dependent variable. For small fish, such as juvenile rockfish, the catch by number was used instead of, or in addition to, the catch by weight. All catch data were logtransformed prior to ANOVA because we expected both fish escapement and shrimp loss to be proportional to the total catch in the control configuration net and because it tends to normalize skewed catch data distributions. The percentage reduction in catch caused by the ladder configuration was estimated relative to the control net using the back transformed catch means.

\section{Results and Discussion}

Seventeen successful hauls provided useable data for comparing catches from the two footrope configurations. Haul duration averaged 1.48 h, with a range of 0.83 to $2.08 \mathrm{~h}$.

The ladder configuration reduced catches of slender sole (Eopsetta exilis) by $79 \%$ and $84 \%$, by weight and number, respectively, relative to the control $(p<0.001$, Table 2 and Fig. 3). The catch of greenstriped rockfish (Sebastes elongatus), a small species of rockfish, was also reduced by $54 \%$ and $49 \%$, by weight and number respectively $(p<0.05$, Table 2 and Fig. 3). The catch of juvenile rockfish was reduced $47 \%$ by number $(p<0.05$, Fig. 3$)$.

Shrimp catch was increased in the net with the ladder configuration by about $6 \%$ over the control net ( $p<0.01$, Table 2, Fig. 4). However, acoustic net measurements suggest that this may be due more to the greater net spread obtained with the ladder configuration than to any direct footrope effects on shrimp catch efficiency. Net spread was measured at 17-18 $\mathrm{m}$ and 16-17 $\mathrm{m}$ for the ladder and control configuration nets, respectively. While the $6 \%$ increase in spread is equal to the increase in shrimp catch observed, it should be noted that the height of the headrope above bottom was somewhat reduced for the net with the ladder configuration, $(4.2 \mathrm{~m}$, versus $4.4 \mathrm{~m}$ ), consequently the difference in the net opening in terms of area was considerably less than $6 \%$. The degree of polishing on a center drop chain indicated that the fishing lines of both nets were running at a comparable distance above the sea bottom, i.e. about $50-70 \mathrm{~cm}$.

The catch of larger fish, including Pacific whiting (Merluccius productus) and most marketable fish, was not significantly different between the two configurations ( $p \geq 0.05$, Table 2$)$. However, the mean catch for both species groups was higher for the net with the ladder configuration (Fig. 4). The mean catch of smelt (Osmeridae, not shown) was also slightly higher with the ladder configuration, but the difference was not statistically significant $(p \geq 0.05)$. For all of these species groups, the increased catch was likely due to the wider spread of the net with the ladder configuration.

TABLE 2. Average percent reduction or increase (in brackets) by number and weight, by species group, for the ladder configuration relative to the control configuration (traditional tickler chain groundline).

\begin{tabular}{lcc}
\hline \hline Species /Group & $\begin{array}{c}\text { Percent Change } \\
\text { By Weight }\end{array}$ & $\begin{array}{c}\text { Percent Change } \\
\text { By Number }\end{array}$ \\
\hline Ocean Shrimp & $(6.2)^{* *}$ & - \\
Pacific whiting & $\mathrm{ns}$ & - \\
Marketable Fish & $\mathrm{ns}$ & - \\
Slender sole & $79.2^{* * *}$ & $83.9^{* * *}$ \\
Smelt & $\mathrm{ns}$ & - \\
Juvenile Rockfish $(<8 \mathrm{~cm})$ & - & $47.4^{*}$ \\
Greenstriped Rockfish & $53.6^{*}$ & $49.0^{*}$ \\
\hline
\end{tabular}

ns $=$ non-significant

$* p<0.05, * * p<0.01, * * * p<0.001$ 


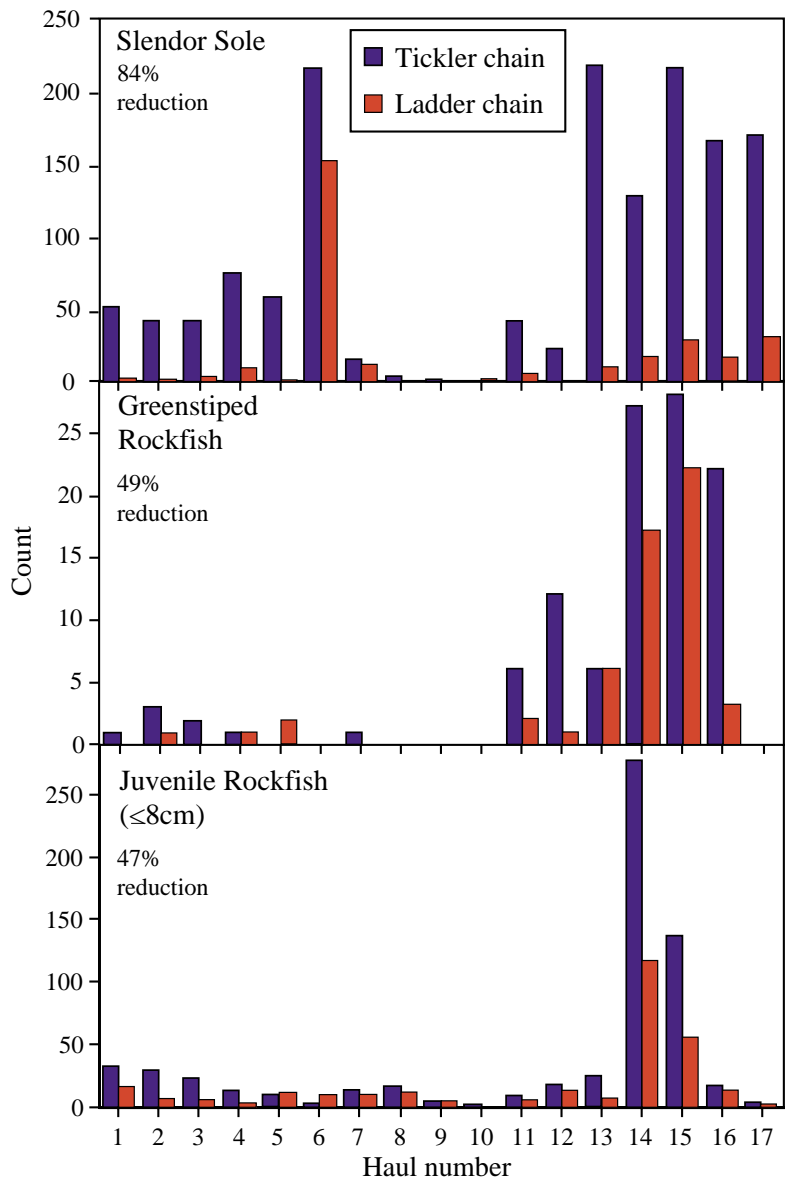

Fig. 3. Catch of slender sole, greenstriped rockfish and juvenile rockfish, by haul, for the tickler chain and ladder/roller configurations.

The most interesting finding of this study was that catches of larger marketable fish were unchanged while those of slender sole (a small flatfish) and small rockfish were greatly reduced with the ladder configuration. These results are consistent with size selective sorting at the footrope as reported by Munro et al., (MS 1997). This could arise from the interaction of a number of factors. Since the maximum swimming speed of fish is a function of body length (Wardle, 1975; He, 1993) larger fish tend to "burst" swim ahead of the footrope, rise higher off bottom, and so are more likely to be captured. Large fish are similar in size to the entire footrope configuration and may perceive and avoid the groundline and fishing line as one unit. Smaller fish on the bottom are roughly equal or smaller than the diameter of the groundline, and may ignore the fishing line running $50-70 \mathrm{~cm}$ above and slightly ahead of the groundline. The tickler chain runs well ahead of the fishing line, and small fish

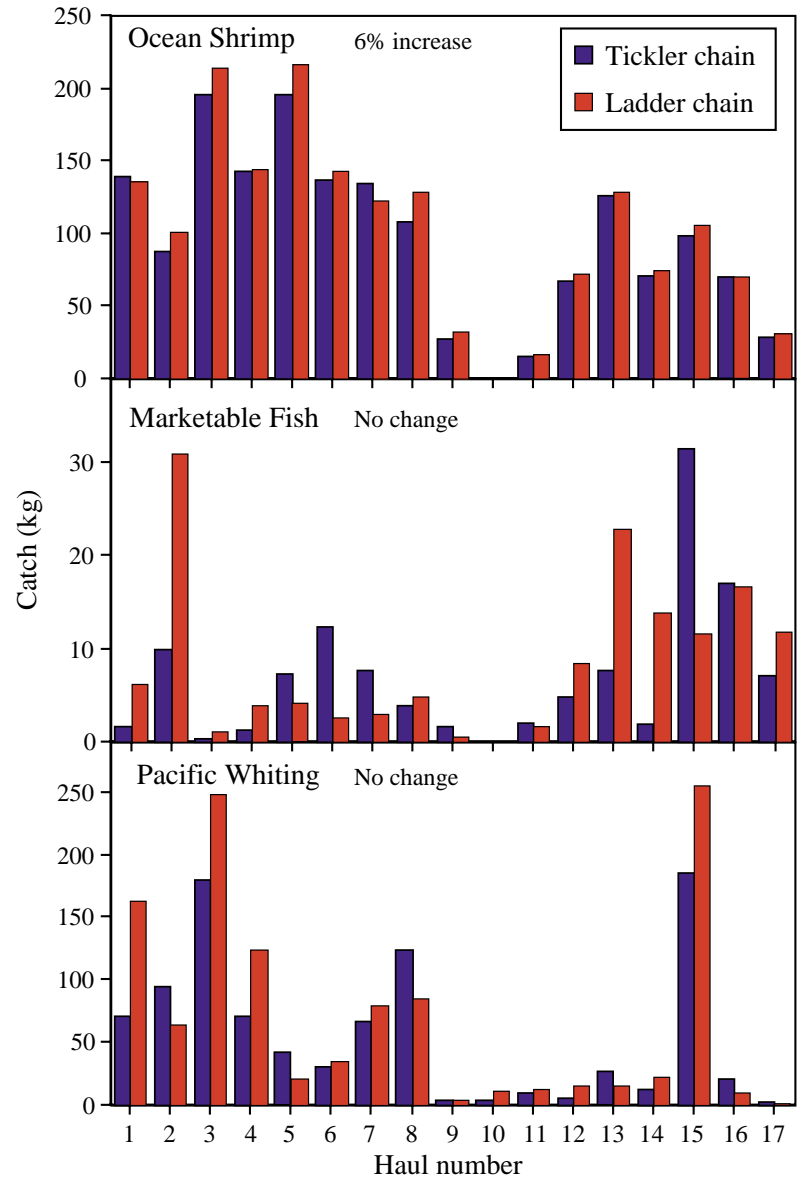

Fig. 4. Catch of ocean shrimp, marketable fish and Pacific whiting, by haul, for the tickler chain and ladder/roller configurations.

probably dart over it and are captured when they continue upward and over the fishing line running close behind. Since the ladder configuration groundline runs just below and slightly behind the fishing line, small fish darting upwards to avoid the groundline may simply run into the meshes at the bottom of the trawl and escape capture. While this seems a reasonable hypothesis, underwater camera work is needed to establish why small fish are less likely to be captured by the ladder configuration.

The lack of any evidence for a reduction in shrimp catch with the ladder configuration suggests that the tickler chain traditionally used in the ocean shrimp fishery may not be necessary to maintain good catch rates. Some veteran ocean shrimp fishers agree. One of these fishers uses no groundline at all, but rather a series of heavy drop chains to maintain the needed height of the fishing line above bottom. This fisher's 
shrimp catch rates are comparable to similar vessels fishing tickler chains. However, other vessel operators maintain that a tickler chain does increase ocean shrimp catch at times. Beardsley (1973) evaluated catches of ocean shrimp with and without a tickler chain on an experimental vertical distribution sampling device. A tickler chain doubled shrimp catches, mainly in the lower sections of the sampling device. An alternative interpretation of our results is that the ladder configuration functions like a tickler chain with respect to shrimp behavior. Vibrations or direct contact of shrimp with the groundline may also stimulate shrimp to jump upwards and into the trawl. If that is the case, then the behaviour of the slender sole and small rockfish which are escaping capture must be very different than that of shrimp. In any case, the need for underwater camera work is indicated.

The vessels and gear used during the growth and development of the ocean shrimp fishery came mainly from the penaeid shrimp fishery in the Gulf of Mexico (Zirges and Robinson, 1980) where tickler chains are necessary to maximize shrimp catch. Consequently, their use in the ocean shrimp fishery is based as much on tradition as necessity. We recommend that further testing be completed to examine this question. If ladder style groundlines, or footropes using only heavy drop chains, can be shown to consistently reduce bycatch of some unwanted species without decreasing shrimp catch rates, then voluntary use of such gear is likely to grow.

\section{Acknowledgements}

This paper was funded in part by a grant/ cooperative agreement from the National Oceanic and Atmospheric Administration. The views expressed herein are those of the author and do not necessarily reflect the views of NOAA or any of its sub-agencies. This project was financed in part with Federal Interjurisdictional Fisheries Act funds (75\% federal, $25 \%$ state of Oregon funds) through the U. S. National Marine Fisheries Service (contract\# NA86FI0265 total 1999 project funds - \$64936 federal, \$21 645 state). Bob Schones, the skipper of the F/V Lady Kaye, helped design the project and supervised all footrope construction and modification. Erica Fruh assisted with the field data collection, as did the crew of the F/V Lady Kaye. Jim Golden and Steve Parker provided reviews of the draft manuscript.

\section{References}

BEARDSLEY, A. 1973. Design and evaluation of a sampler for measuring the near-bottom vertical distribution of pink shrimp (Pandalus jordani). Fish. Bull., 71(1): 243253.

HANNAH, R. W., S. A. JONES, and V. J. HOOVER. 1996. Evaluation of fish excluder technology to reduce finfish by-catch in the pink shrimp trawl fishery. Oregon Dept. Fish Wildl., Information Rept. Ser., Fish., No. 96-4, 46 p.

HE, P. 1993. Swimming speeds of marine fish in relation to fishing gears. ICES Mar. Sci. Symp., 196: 183-189.

HIGH, W. L., I. E. ELLIS, and L. D. LUSZ. 1969. A progress report on the development of a shrimp trawl to separate shrimp from fish and bottom dwelling animals. Comm. Fish. Rev., 31(3): 20-33.

ISAKSEN, B., J. W. VALDEMARSEN, R. B. LARSEN, and L. KARLSEN. 1992. Reduction of finfish by-catch in shrimp trawl using a rigid separator grid in the aft belly. Fish. Res., 13: 335-352.

JONES, S. A., R. W. HANNAH, and J. T. GOLDEN. 1996. A survey of trawl gear employed in the fishery for ocean shrimp Pandalus jordani. Oregon Dept. Fish Wildl., Information Rept. Ser., Fish., No. 96-6, 23 p.

LUKAS, J., and C. CARTER. 1998. 1996 pounds and value of commercially caught fish and shellfish landed in Oregon. Oregon Dept. of Fish and Wildlife, $120 \mathrm{p}$.

MUNRO, P. T., K. L. WEINBERG, and D. SOMERTON. MS 1997. Estimating size dependent capture rates at the footrope of two different kinds of survey trawls. ICES C.M. Doc., No. W:06, 18 p.

PACIFIC FISHERY MANAGEMENT COUNCIL. 1981. Discussion draft fishery management plan for the pink shrimp fishery off Washington, Oregon, and California. PFMC, $169 \mathrm{p}$.

WARDLE, C. S. 1975. Limit of fish swimming speed. Nature, 225: $725-727$.

ZIRGES, M. H., and J. G. ROBINSON. 1980. The Oregon pink shrimp fishery, management history and research activities. Oregon Dept. Fish Wildl., Information Rept. Ser. Fish., No. 80-1, 15 p. 
